\title{
Assessment of the Deepwater Horizon oil spill impact on Gulf coast microbial communities
}

\author{
Regina Lamendella ${ }^{1,2 *}$, Steven Strutt ${ }^{2}$, Sharon Borglin ${ }^{1}$, Romy Chakraborty ${ }^{1}$, Neslihan Tas ${ }^{1}$, \\ Olivia U. Mason ${ }^{1,3}$, Jenni Hultman ${ }^{1,4}$, Emmanuel Prestat ${ }^{1}$, Terry C. Hazen ${ }^{1,5,6}$ and Janet K. Jansson ${ }^{1,7}$ \\ 1 Lawrence Berkeley National Laboratory, Earth Sciences Division, Ecology Department, Berkeley, CA, USA \\ 2 Biology Department, Juniata College, Huntingdon, PA, USA \\ ${ }^{3}$ Department of Earth, Ocean and Atmospheric Science, Florida State University, Tallahassee, FL, USA \\ ${ }^{4}$ Department of Food Hygiene and Environmental Health, University of Helsinki, Helsinki, Finland \\ ${ }^{5}$ Department of Civil and Environmental Engineering, University of Tennessee, Knoxville, TN, USA \\ ${ }^{6}$ Oak Ridge National Laboratory, Biosciences Division, Oak Ridge, TN, USA \\ 7 Department of Energy, Joint Genome Institute, Walnut Creek, CA, USA
}

\section{Edited by:}

Joel E. Kostka, Georgia Institute of Technology, USA

\section{Reviewed by:}

Peter Golyshin, Bangor University, UK

Kostas Konstantinidis, Georgia Institute of Technology, USA

\section{*Correspondence:}

Regina Lamendella, Lawrence Berkeley National Laboratory, Earth Sciences Division, Ecology Department, 1 Cyclotron Road, Berkeley, CA 94720, USA e-mail: jrjansson@lbl.gov
One of the major environmental concerns of the Deepwater Horizon oil spill in the Gulf of Mexico was the ecological impact of the oil that reached shorelines of the Gulf Coast. Here we investigated the impact of the oil on the microbial composition in beach samples collected in June 2010 along a heavily impacted shoreline near Grand Isle, Louisiana. Successional changes in the microbial community structure due to the oil contamination were determined by deep sequencing of 16S rRNA genes. Metatranscriptomics was used to determine expression of functional genes involved in hydrocarbon degradation processes. In addition, potential hydrocarbon-degrading Bacteria were obtained in culture. The $16 \mathrm{~S}$ data revealed that highly contaminated samples had higher abundances of Alpha- and Gammaproteobacteria sequences. Successional changes in these classes were observed over time, during which the oil was partially degraded. The metatranscriptome data revealed that $\mathrm{PAH}, \mathrm{n}$-alkane, and toluene degradation genes were expressed in the contaminated samples, with high homology to genes from Alteromonadales, Rhodobacterales, and Pseudomonales. Notably, Marinobacter (Gammaproteobacteria) had the highest representation of expressed genes in the samples. A Marinobacter isolated from this beach was shown to have potential for transformation of hydrocarbons in incubation experiments with oil obtained from the Mississippi Canyon Block 252 (MC252) well; collected during the Deepwater Horizon spill. The combined data revealed a response of the beach microbial community to oil contaminants, including prevalence of Bacteria endowed with the functional capacity to degrade oil.

Keywords: hydrocarbons, 16S rRNA gene, metatranscriptomics, oil spill, microbial communities

\section{INTRODUCTION}

The Deepwater Horizon oil spill was the largest accidental marine oil spill in the history of the oil industry, spewing an estimated 4.1 million barrels of crude oil into the Gulf of Mexico (Zukunft, 2010). In addition, 1.84 million gallons of chemical dispersants were applied to assist in oil dispersal (The Federal Intragency Solutions Group: Oil Budget Calculator Science and Engineering Team, 2010). Physical barriers, direct collection from the wellhead, skimming, and burning were also implemented in order to mitigate the effects of the spill. Despite significant efforts to protect hundreds of miles of beaches, wetlands, and estuaries from oil, it began washing up on the Gulf Coast by early May 2010 (OSAT-2, 2011). Most recent estimates indicate that up to $22 \%$ of the 4.1 million barrels of oil was either trapped under the surface of the water as sheen, carried on the water surface as conglomerated tar (Lubchenco et al., 2010; Kimes et al., 2013), or deposited onto surface sediments (US Coast Guard, USGS, and NOAA, 2010; Mason et al., 2014). Some of the oil washed ashore where it was either collected or became entrained in sand and sediments. The contamination of beach ecosystems raised considerable concern due to the potential for detrimental environmental and economic impacts in the Gulf region (McCrea-Strub et al., 2011; Sumaila et al., 2012).

Initial research studies of the Gulf oil spill mainly focused on the fate of the oil in the water column. These studies highlighted the significant contribution of microorganisms toward the degradation of oil in a deep-sea hydrocarbon plume (Camilli et al., 2010; Hazen et al., 2010; Valentine et al., 2010, 2012; Redmond and Valentine, 2011; Baelum et al., 2012; Mason et al., 2012), and in particular a rapid response of members of the Gammaproteobacteria to hydrocarbon inputs. Specifically, there was an initial increase in relative abundance of members of the Oceanospirillales (Hazen et al., 2010; Redmond and Valentine, 2011; Mason et al., 2012), followed by members of the genera Colwellia and Cycloclasticus during later sampling periods (Redmond and Valentine, 2011; Valentine et al., 2012; Dubinsky et al., 2013). 
Comparably less is known about the fate of the oil that reached the shore during the Deepwater Horizon spill. One study by Kostka et al. (2011) investigated the impact of the oil on beach samples collected several months after the spill occurred (July and September 2010) at municipal Pensacola Beach, Florida. By 16S rRNA gene sequencing, the authors found that the spill had a significant impact on the abundance and community composition of indigenous bacteria in beach sand with increases in many members of the Alpha- and Gammaproteobacteria, including some well-known hydrocarbon degraders (Alcanivorax and Marinobacter) (Yakimov et al., 1998; Alonso-Gutiérrez et al., 2009). In the same study, several proteobacterial isolates, capable of growth on oil as their sole carbon source, were obtained from the contaminated samples (Kostka et al., 2011).

Here we aimed to determine the response of indigenous beach microbial communities to the oil that washed ashore early in the spill history. We focused our efforts on Elmers's Beach, Grand Isle, LA. This location was one of the most heavily oiled beaches in the Gulf, where oil began washing up onto the beach in early May 2010 (OSAT-2, 2011). A total of 153 oil contaminated and uncontaminated samples were collected at three time points in June 2010, while the oil continued to accumulate on the beach. The well was finally capped on July 15, 2010 and declared sealed on September 19, 2010.

We performed targeted 16S rRNA gene sequencing and total RNA sequencing (metatranscriptomics) to determine the composition of the microbial community, as well as to elucidate which members were actively degrading hydrocarbons in oiled samples. In addition, we isolated putative MC252 oil degrading microorganisms and studied their potential for hydrocarbon degradation. This study revealed a succession in the microbial community structure on the beach during early time points in the Deepwater Horizon oil spill. This study also represents the first use of metatranscriptome data to highlight the expression of genes involved in hydrocarbon transformations in a coastline community.

\section{MATERIALS AND METHODS SAMPLE COLLECTION}

Beach sand cores were collected on Elmer's Beach $(29.1782853,-90.0684072)$ at three time points on $03 / 06 / 2010$ $(n=7), 21 / 06 / 2010(n=7)$, and 29/06/2010 $(n=3)$. Sand cores (10-20 cm deep) were taken by manual insertion of $40 \mathrm{~cm}$ long polybutyrate plastic liners into the sand. The cores were taken from locations submerged in the water close to the waterline, at the waterline, and inland. To circumvent potential contamination from the polybutyrate liners, each sand core was sub-cored using a $25 \mathrm{~mm}$ diameter sterile copper pipe, and sectioned into $3 \mathrm{~cm}$ depth intervals. Additionally, tar-like samples found on the surface of the beach $(n=24)$ were collected at each sampling period by aseptically scraping approximately $2-10 \mathrm{~g}$ into sterile $50 \mathrm{~mL}$ conical tubes. All samples were kept on ice in the field and were maintained at $4^{\circ} \mathrm{C}$ until further processing. Detailed information about all the samples, relating to location, date, core depth, and hydrocarbon composition can be found in Supplemental Table S1.

\section{ACRIDINE ORANGE DIRECT COUNTS}

Approximately $1 \mathrm{~g}$ of each sample was homogenized and diluted in $1 \mathrm{X}$ PBS. Samples were filtered through a $0.2 \mu \mathrm{m}$ pore size black polycarbonate membrane (Whatman International Ltd., Piscataway, NJ). Filtered cells were stained with $25 \mathrm{mg} / \mathrm{mL}$ acridine orange for $2 \mathrm{~min}$ in the dark. Unbound acridine orange was filtered through the membrane with $10 \mathrm{~mL}$ filter sterilized 1X PBS (Sigma Aldrich Corp., St. Louis, MI) and the rinsed membrane was mounted on a slide for microscopy. Cells were imaged with a FITC filter on a Zeiss Axioskop (Carl Zeiss, Inc., Germany).

\section{PETROLEUM HYDROCARBON CONCENTRATIONS}

Total petroleum hydrocarbon $(\mathrm{TPH})$ concentrations were determined using previously published procedures (Hazen et al., 2010) with the following modifications: $500 \mu \mathrm{L}$ of chloroform were added to $500 \mathrm{mg}$ of sample and then vortexed thoroughly, shaken for $2 \mathrm{~min}$ and sonicated for $2 \mathrm{~min}$. The samples were incubated at room temperature for $1 \mathrm{~h}$, centrifuged at 2,000 rpm for $5 \mathrm{~min}$, and $50 \mu \mathrm{L}$ of the extract was removed for analysis on an Agilent $6890 \mathrm{~N}$ GC/FID (Santa Clara, CA). The GC was operated with an injector temperature of $250^{\circ} \mathrm{C}$ and detector temperature of $300^{\circ} \mathrm{C}$, following a temperature program of $50^{\circ} \mathrm{C}$ for $2 \mathrm{~min}$, ramped by $5^{\circ} \mathrm{C} / \mathrm{min}$ until reaching $300^{\circ} \mathrm{C}$ and subsequently held for $15 \mathrm{~min}$. $\mathrm{TPH}$ were quantified by integrating all the peaks from 20 to $60 \mathrm{~min}$ and comparing to oil standards $(0-200 \mathrm{mg} / \mathrm{L})$ obtained from the Macondo source well during the Deepwater Horizon spill.

PAH and alkane compound analysis was completed on the Agilent $6890 \mathrm{~N}$ equipped with a 5972 mass selective detector and operated in SIM/SCAN mode. The injection temperature was $250^{\circ} \mathrm{C}$, detector temperature was $300^{\circ} \mathrm{C}$, and column used was $60 \mathrm{~m}$ Agilent HP-1 MS with a flow rate of $2 \mathrm{~mL} / \mathrm{min}$. The oven temperature program included a $50^{\circ} \mathrm{C}$ hold for $3 \mathrm{~min}$ ramped to $300^{\circ} \mathrm{C}$ at $4^{\circ} \mathrm{C} / \mathrm{min}$ with a final $10 \mathrm{~min}$ hold at $300^{\circ} \mathrm{C}$. Compound identification was determined from selective ion monitoring coupled with comparison to known standards and compound spectra in the NIST 08 MS library. Biomarker profiles were obtained by running the same samples in SIM mode targeting ions 191 for hopanes and 217 for steranes. Monitoring these ions has been widely used for oil source identification and degree of biodegradation (Venosa et al., 1997; Volkman et al., 1983; Greenwood and Georges, 1999; Hauser et al., 1999; Rosenbauer et al., 2010) and was utilized here to compare oil biomarker fingerprint to oil from the MC 252 source oil (Macondo crude). A proxy for biodegradation within the samples was calculated using the depletion of $\mathrm{C}_{25}$ with respect to $\mathrm{C}_{17}$ and the ratio of branched to aliphatic alkanes.

\section{DNA EXTRACTION}

Samples were extracted in duplicate using a modified Miller DNA extraction method (Miller et al., 1999). Approximately $0.5 \mathrm{~g}$ of each sample was placed into an FT500-ND Pulse Tube (Pressure BioSciences, Inc., USA). $300 \mu \mathrm{L}$ of Miller phosphate buffer and $300 \mu \mathrm{L}$ of Miller SDS lysis buffer were added and mixed. $600 \mu \mathrm{L}$ phenol:chloroform:isoamyl alcohol $(25: 24: 1)$ were then added, and the tubes were subjected to 25 cycles of 35,000 psi for $10 \mathrm{~s}$ and ambient pressure for $10 \mathrm{~s}$, to improve cell lysis. The mixture was transferred to a Lysing Matrix E tube (MP Biomedicals, 
Solon, $\mathrm{OH}$ ) and subjected to bead-beating at $5.5 \mathrm{~m} / \mathrm{s}$ for $45 \mathrm{~s}$ in a FastPrep (MP Biomedicals, Solon, $\mathrm{OH}$ ) instrument. The tubes were centrifuged at $16,000 \times \mathrm{g}$ for $5 \mathrm{~min}$ at $4^{\circ} \mathrm{C}$ and $540 \mu \mathrm{L}$ of supernatant was transferred to a $2 \mathrm{~mL}$ tube with addition of an equal volume of chloroform. Tubes were mixed and then centrifuged at $10,000 \times \mathrm{g}$ for $5 \mathrm{~min}$, after which $400 \mu \mathrm{L}$ of the aqueous phase was transferred to another tube and 2 volumes of Solution S3 (MoBio, Carlsbad, CA) were added and mixed by inversion. The subsequent clean-up methods were based on the MoBio Soil DNA extraction kit according to the manufacturer's instructions. Samples were recovered in $60 \mu \mathrm{L} 10 \mathrm{mM}$ Tris and stored at $-20^{\circ} \mathrm{C}$.

\section{COMMUNITY PROFILING AND STATISTICAL METHODS}

Small subunit (SSU) rRNA gene sequences were amplified from duplicate DNA extractions using the primer pair 926f/1392r as previously described (Kunin et al., 2010). The reverse primer included a $5 \mathrm{bp}$ barcode for multiplexing of samples during sequencing. Emulsion PCR and sequencing of the PCR amplicons was performed at DOE's Joint Genome Institute following manufacturer's instructions for the Roche 454 GS FLX Titanium technology, with the exception that the final dilution was $1 \mathrm{e}-8$ (Allgaier et al., 2010).

Sequence reads were submitted to the PyroTagger computational pipeline (Kunin and Hugenholtz, 2010) where the reads were quality filtered, trimmed, dereplicated and clustered at $97 \%$ sequence identity. OTU tables generated from Pyrotagger were then imported into the QIIME pipeline (Caporaso et al., 2010) for further analyses. The number of sequence reads in each sample varied, therefore, the dataset was rarified. Alpha diversity calculations were performed on rarified data.

Multivariate community analysis was performed within PCORD 5 software (McCune et al., 2002) using normalized OTU data (family-level and OTU level). OTUs found in less than two samples were removed. Outliers were removed from the dataset using PCORD 5 with a cutoff of two standard deviations. The Bray-Curtis distance measure was used for non-metric multidimensional scaling (nMDS). Pearson correlation coefficients were calculated for metadata variables and each axis of the nMDS.

\section{RNA EXTRACTION, AMPLIFICATION, AND SEQUENCING}

Total RNA was extracted from three of the oil contaminated samples as previously described (Kasai et al., 2001) and amplified using the Message Amp II-Bacteria Kit (Ambion, Austin, TX) following the manufacturer's instructions. First strand synthesis of cDNA from the resulting antisense RNA was carried out with the SuperScript III First Strand Synthesis System (Invitrogen, Carlsbad, CA). The SuperScript Double-Stranded cDNA Synthesis Kit (Invitrogen, Carlsbad, CA) was used to synthesize double stranded cDNA. cDNA was purified using a QIAquick PCR purification kit (Qiagen, Valencia, CA) and poly(A) tails were removed by digesting purified DNA with BpmI for $3 \mathrm{~h}$ at $37^{\circ} \mathrm{C}$. Digested cDNA was purified with QIAquick PCR purification kit (Qiagen, Valencia, CA). RNA was prepared for sequencing using the Illumina Truseq kit following the manufacturer's guidelines. Each library was sequenced on one lane of the Illumina HiSeq platform using the 150 bp Paired-end technology resulting in a total of $57 \mathrm{~Gb}$ of sequence data for all three samples.

\section{METATRANSCRIPTOMICS DATA ANALYSIS}

Raw Illumina sequence reads from each of three surfacecontaminated samples (one from each sampling date) were trimmed using the CLC Genomics Workbench v5.0.1 with a quality score limit of 0.05 . Phred quality scores (Q) were imported into the genomics workbench, where they were converted to error probabilities, using $\mathrm{p}_{\text {error }}=10^{\mathrm{Q} /-10}$ and were trimmed using a limit of 0.05 as described in the CLC Workbench Manual (http:// www.clcbio.com).

Sequences shorter than $50 \mathrm{bp}$ in length and all adapter sequences were removed. To characterize the active microbial community members, unassembled reads were searched against the Greengenes (DeSantis et al., 2006) database of 16S rRNA genes using BLASTn with a bit score cutoff of $>100$.

Transcript profiles from each sample were determined by first subjecting trimmed unassembled reads from each sample to ORF calling using Prodigal (Hyatt et al., 2010). Resulting ORFs were compared to a translated in-house hydrocarbon gene database using BLASTp. This database was constructed using all KEGG genes involved in hydrocarbon degradation from the KEGG database (Kanehisa and Goto, 2000). For the resulting BLAST outputs, the highest bit score was selected ( $\min$ bit score $>40$ ). Metatranscriptome data from each sample were normalized to RecA expression levels. A pairwise statistical comparison of the BLAST analyses was carried out using STAMP (Parks and Beiko, 2010) using a two-sided Chi-square test (with Yates correction) statistic with the DP: Asymptotic-CC confidence interval method and the Bonferroni multiple test correction. A $p$-value of $<0.05$ was used with a double effect size filter (difference between proportions effect size $<1.00$ and a ratio of proportions effect size $<2.00$. The metatranscriptome from the June 29 sampling date yielded an insufficient number of transcripts after quality filtering, thus subsequent analyses of the metatranscriptome data focused on the June 3 and June 21 samples.

Paired-end Illumina reads from each of the June 3 and June 21 samples were assembled using the De Novo Assembly Tool within the CLC Genomics Workbench at a word size of 20 and a bubble size of 50. Reads were scaffolded onto the contigs, which were submitted to MG-RAST (Meyer et al., 2008) for annotation. In MG-RAST, functional tables were generated for each sample against the $\mathrm{KO}$ annotation database, using default parameters (1e-5 maximum $e$-value cutoff, $60 \%$ minimum sequence identity, and $15 \mathrm{bp}$ of minimum alignment length). To determine which organisms express genes involved in hydrocarbon degradation, contigs for each enzyme mapping to a xenobiotic pathway were annotated against the M5NR database for best-hit organismal classification using the default parameters. Using default parameters for the best-hit classification tool in MG-RAST, contigs were annotated against the Greengenes database to further assess presence of microbial community members through $16 \mathrm{~S}$ rRNA transcripts. Recruitment plots were generated using a maximum e-value cutoff of $1 \mathrm{e}-3$ and a $\log _{2}$ abundance scale. Contigs mapping to xenobiotic pathways were rarefied to a depth of 20,000 annotated contigs each. Xenobiotic degradation maps annotated 
using Kegg Orthology (KO) were downloaded from the KEGG server in KGML format and manually colored using the KGML editor (Klukas and Schreiber, 2007). Charts were generated from the Krona template (Ondov et al., 2011).

Assembled data are publicly available in the MG-RAST database under project ID 7309. Raw reads were submitted to NCBI's sequence read archive under project ID SUB442498.

\section{ENRICHMENTS AND ISOLATIONS}

Bacteria were isolated from sand cores and contaminated beach samples after incubation under aerobic conditions with $100 \mathrm{ppm}$ Macondo oil (MC 252) in either Marine broth medium (Difco), Minimal marine medium (Baelum et al., 2012) or Synthetic minimal marine medium. Synthetic Minimal marine medium was prepared as follows: For $1 \mathrm{~L}$, autoclaved separately $850 \mathrm{~mL}$ of $20 \mathrm{~g} \mathrm{NaCl}, 0.67 \mathrm{~g} \mathrm{KCl}, 10 \mathrm{~mL}$ each of mineral and vitamin mixes (Coates et al., 1995), $100 \mathrm{~mL}$ of $30 \mathrm{mM}$ phosphate buffer (pH 7.5), and added to $50 \mathrm{~mL}$ of $10.1 \mathrm{MgCl}_{2} \cdot 6 \mathrm{H}_{2} \mathrm{O}+1.52 \mathrm{~g} \mathrm{CaCl}_{2} \cdot 2 \mathrm{H}_{2} \mathrm{O}$. Enrichments that resulted in an increase in turbidity, in addition to an increase in cell number by microscopic observations, were transferred periodically into fresh media. After $3-4$ transfers, colonies were obtained by plating on the respective agar plates and were incubated for 1 week. Isolates were obtained from single colonies and incubated aerobically in modified Synthetic Seawater medium with $100 \mathrm{ppm}$ MC252 oil as the sole carbon source. Within a few days, the oil initially observed as a thin layer floating on top disappeared with a concurrent increase in cell number. At this point, DNA was extracted from the cultures using the MoBio UltraClean Microbial DNA Isolation Kit (MoBio Inc, Carlsbad, CA). PCR amplification was conducted using universal bacterial $16 \mathrm{~S}$ rRNA gene primers $27 \mathrm{~F}$ and $1492 \mathrm{R}$ in $50 \mathrm{ul}$ reactions, with a final concentration of $0.025 \mathrm{unit} / \mu \mathrm{l} \mathrm{Taq}, 0.2 \mathrm{mM}$ dNTPs, $15 \mathrm{ng}$ of DNA template, and $0.04 \mu \mathrm{M}$ primer. Initial denaturation was at $95^{\circ} \mathrm{C}$ for $180 \mathrm{~s}$, followed by 25 cycles of melting at $95^{\circ} \mathrm{C}$ for $30 \mathrm{~s}$, annealing at $54^{\circ} \mathrm{C}$ for $30 \mathrm{~s}$, extension at $72^{\circ} \mathrm{C}$ for $60 \mathrm{~s}$. This was followed by a final extension of $10 \mathrm{~min}$ at $72^{\circ} \mathrm{C}$ and samples were held at $4^{\circ} \mathrm{C}$ on completion of amplification. Verified $16 \mathrm{~S}$ amplicons were purified using the procedure provided in the MoBio Ultraclean PCR Clean-up kit (MoBio, Carlsbad, CA). Samples were sequenced using the Applied Biosystems ABI 3730XL DNA Analyzers with the BigDye Terminator V3.1 Cycle Sequencing Kit (Applied Biosystems, Carlsbad, CA), according to the manufacturer's instructions.

\section{OIL DEGRADATION WITH ISOLATES}

Different selective minimal media were prepared to test individual isolates for their ability to degrade oil, since the isolates belonged to different genera and had different nutritional requirements. Marinobacter isolate 33 was grown in MC252 oil amended with minimal marine media. Roseobacter isolate 36 was grown in modified Sistrom's Minimal Medium (Sistrom, 1962). Oil degradation experiments were set up in $30 \mathrm{~mL}$ of respective media amended with 20 ppm MC252 oil and 0.1 ppm COREXIT 9500, inoculated with the respective bacterial cultures, and incubated at room temperature in the dark. The inoculant was grown in the respective minimal medium amended with $0.1 \%$ Yeast extract to promote biomass. Prior to inoculation, cells were pelleted and washed in phosphate buffer ( $\mathrm{pH}$ 7.5) to remove any carry over of media constituents. Heat killed cells (autoclaved) were used as negative controls, by $10 \%$ inoculation into experimental bottles containing oil and media.

At periodic intervals during the incubations, experimental bottles were sacrificed for hydrocarbon analyses to determine the extent of oil degradation. All glassware used in extraction and analyses was muffled at $500^{\circ} \mathrm{C}$ for $4 \mathrm{~h}$ prior to use. To extract hydrocarbons, the entire culture volume $(30 \mathrm{ml})$ was transferred from the experimental bottles to a $50 \mathrm{~mL}$ glass culture tube with a Teflon-lined lid. The empty bottles were extracted three times with $2 \mathrm{~mL}$ of chloroform (BDH, ACS grade) to assay hydrocarbons sorbed to the glass and the rinses were added to the $50 \mathrm{~mL}$ tube. This mixture was vortexed for $1 \mathrm{~min}$ and extracted for $1 \mathrm{~h}$, after which they were re-vortexed and centrifuged at $2000 \mathrm{rpm}$ for $15 \mathrm{~min}$ to aid the separation of the chloroform from the aqueous media layer. The chloroform layer was removed with a glass pipette into a GC vial and analyzed as described above.

\section{RESULTS \\ STATE OF THE SAMPLING SITE}

On June 3, 2010, the sampling site was almost completely covered to the tidal berm with viscous oil. Seawater washing up on the shore contained large, amorphous globules of oil. On June 21, 2010 , the beach no longer contained visible globules of oil and the surface of the sampling site was no longer covered in oil. Instead, the oil present was in the form of small dried globules, less than $2 \mathrm{~cm}$ in diameter. By June 29,2010, oil and oil mixed with foam were evident at the sampling site. The beach surface was rust in color and a light sheen of oil was noted on the seawater surface.

\section{CHEMICAL ANALYSIS}

The hydrocarbon profiles of the beached oil and contaminated sand core samples showed a clear correspondence to the MC252 oil (Supplemental Figure. S1). Total petroleum hydrocarbons (TPH) ranged from $0 \mathrm{mg} / \mathrm{kg}$ to $2072 \mathrm{mg} / \mathrm{kg}$. Several components in the oil decreased over time and were significantly depleted by June 21 and June 29 sampling dates. Specifically, there was a depletion of shorter alkanes $\left(\mathrm{C}_{17}-\mathrm{C}_{20}\right)$ and a corresponding higher relative amount of longer chain alkanes $\left(>\mathrm{C}_{20}\right)$ and branched alkanes. Cluster analysis of hydrocarbons revealed a clustering of the samples according to the level of hydrocarbon contamination (Supplemental Figure. S2). PAHs were detected in more than one third of the contaminated samples. Three-ring PAHs including, fluorene, anthracene, and phenanthracene and four-ring PAHs, including chrysene and pyrene, were highest in concentration of the measured $\mathrm{PAH}$ compounds, while naphthalene and other two-ring compounds were present in lower amounts and were nearly completely depleted in the less contaminated and uncontaminated samples from all time points (Supplemental Figure S2).

\section{MICROBIAL COMMUNITY ANALYSES}

Cell counts ranged from $10^{5}$ cells $\mathrm{g}^{-1}$ in uncontaminated samples to more than $10^{7}$ cells $\mathrm{g}^{-1}$ in highly contaminated, beached oil samples and this difference was significant $(t$-test; $p=2.97 \times$ $\left.10^{-5}\right)$. Therefore, there was a significant increase in microbial cell 
density as a result of the hydrocarbon influx on the beach, as previously reported by (Kostka et al., 2011).

We retrieved $>1.6$ million non-chimeric, quality filtered $16 \mathrm{~S}$ rRNA gene sequences from a total of 153 oiled and uncontaminated samples, yielding more than 11,000 sequences per sample. The sequence data were dominated by OTUs corresponding to Alpha- and Gammaproteobacteria (Figure 1). Several OTUs that were abundant in the oil-contaminated samples corresponded to taxa with members known to degrade hydrocarbons, including Rhodobacteraceae, Alteromondaceae, Pseudomonadaceae, Chromatiaceae, Alcanivoraceae, and other families within the Oceanospiralles. Samples with the highest concentrations of hydrocarbons had higher relative abundances of Alphaproteobacteria (Figure 1).

Non-metric multidimensional scaling (nMDS) analysis revealed a pronounced response of the microbial community to oil contamination (Figure 2). Samples with high TPH concentrations clustered separately from less contaminated samples (Pearson correlation to Axis $1 ; r=0.971$ ). In addition, the TPH concentration was inversely related to several alpha diversity measures (Figure 2 and Supplemental Figure S3). Co-inertia analyses revealed that the microbial communities differed significantly between the two types of contaminated samples: beached oil and oil-contaminated sand ( $p$-value $<0.001)$. The beached-oil samples also clustered separately by time (Pearson correlation to Axis $1 ; r=0.869$ ), suggesting temporal shifts in the microbial community as a response to the oil spill (Figure 2B and Supplemental Table S2). The depletion in TPH was also positively correlated with time of sampling for all of the contaminated samples. Shifts in the microbial community aligned with continuous disappearance of hydrocarbons during the sampling period (Supplemental Table S2 and Table S3). Several PAHs and aliphatic hydrocarbon components were among the highest factors that correlated to Axis 2 on the nMDS plots (Figure 2C and Supplemental Table S3). Pearson correlations revealed that Rhodobacteraceae and Alteromonadaceae were most highly correlated with hydrocarbon concentrations in the contaminated samples (Supplemental Table S4) with genus and species-specific differences within sand and beached oil matrices. For example, sequences with closest homology to Rhodobacter sp., Jannachia sp., and Marinobacter lutaoensis had the highest correlation to beached oil samples (Supplemental Table S5), while Ruegeria sp., Jannachia sp., Alishewanella baltica, and Pseudomonas pachastrellae correlated with contaminated sand samples (Supplemental Table S6). Of these highest correlating OTUs, the Marinobacter and Pseudomonas genera were the most prevalent and abundant OTUs in the dataset, comprising up to 7 and $4 \%$ of the total community, respectively. It should also be noted, that microbial community composition and hydrocarbon profiles were highly correlated (Mantel test; $t>0, p=0.00000$, $r=0.6104)$.

\section{METATRANSCRIPTOMICS OF OIL CONTAMINATED SAMPLES}

In order to assess which hydrocarbon degradation genes were expressed, we studied the metatranscriptomic profiles of representative heavily oiled samples. Approximately 380 million paired end sequences ( $57 \mathrm{~Gb}$ ) were retrieved from three beached oil samples, one from each sampling date (June 3, June 21, June 29). Our goal was to determine what types of genes were expressed in the beach community as a whole in response to heavy oil contamination. We found that $40-67 \%$ of the quality filtered reads contained ribosomal RNA genes, which was not surprising considering rRNA depletion was not applied to these samples prior to sequencing, given the low RNA yields. When analyzing which taxa were most prevalent in the rRNA from the metatranscriptomes, we saw similar trends to the 16S rRNA microbial community analysis. Metatranscriptome data matching the Greengenes SSU database were dominated by the proteobacteria (74\%), more specifically the Alteromonadales (30\%), Oceanospirillales (11\%), and the Rhodobacterales (8\%). Further,

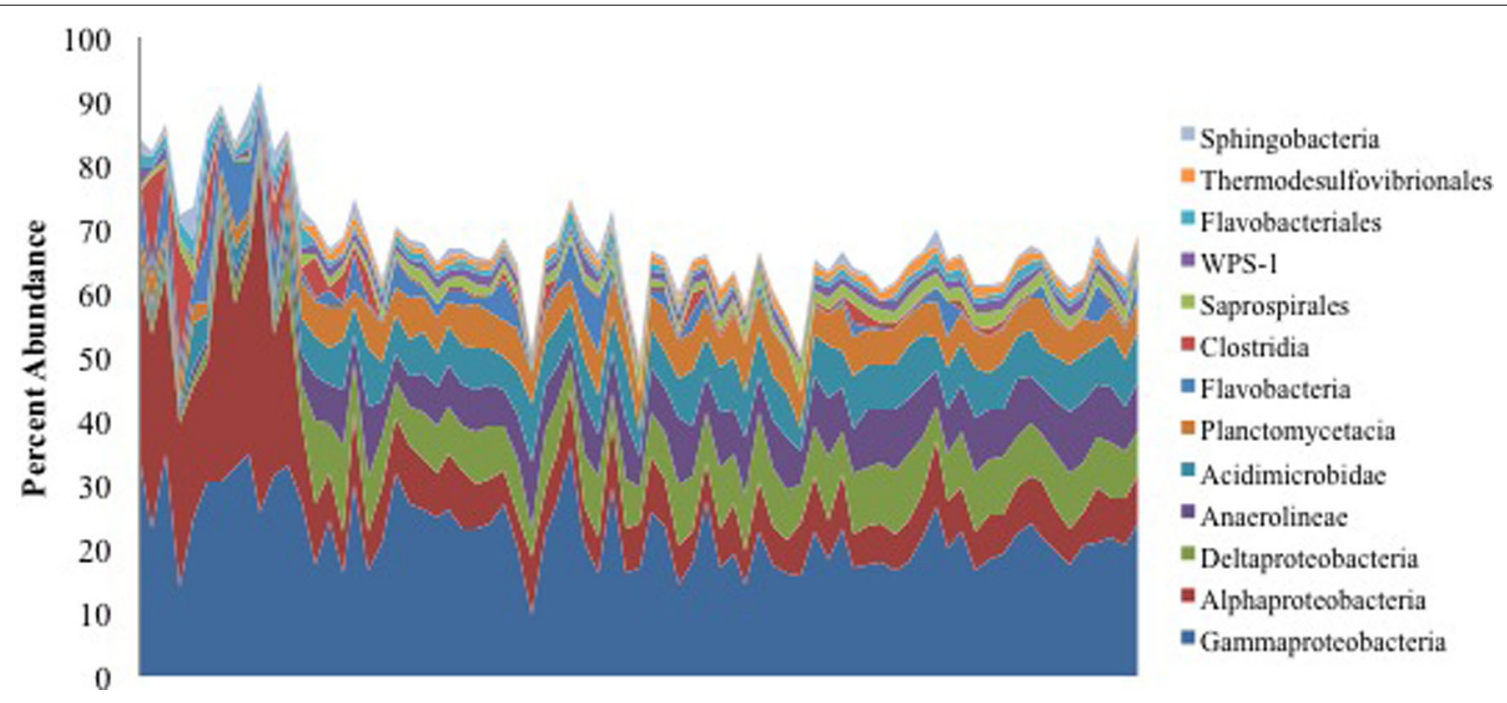

FIGURE 1 | Percent abundance of the $\mathbf{1 3}$ most abundant bacterial classes using $\mathbf{1 6 S}$ rRNA gene sequences. Samples are ordered from highest to lowest $\mathrm{TPH}$ concentration, left to right. 


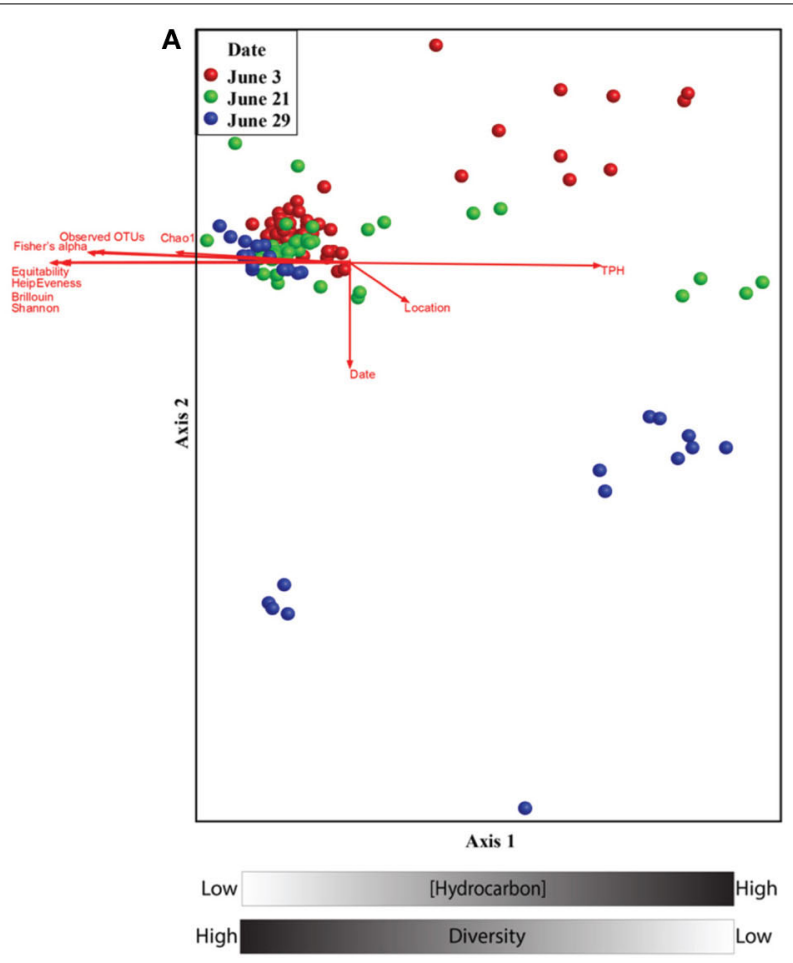

B

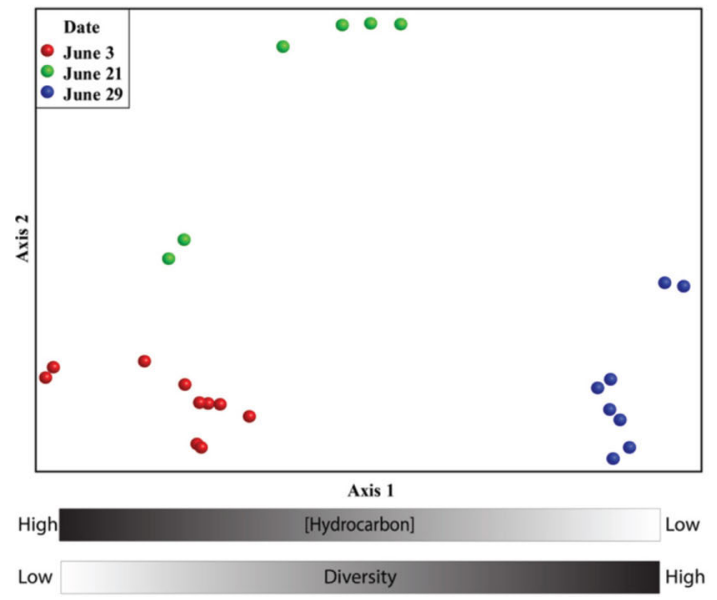

FIGURE 2 | (A) Non-metric multidimensional scaling ordination of beached oil and sand samples based on the relative abundance pyrotag sequences assigned to family-level taxonomy. The ordination plot was rotated to maximize the degree of correlation with the total petroleum hydrocarbon variable. A two dimensional solution was found and the final stress was 0.023. (B) Non-metric multidimensional scaling ordinations of beached oil based on the relative abundance pyrotag sequences assigned to family-level
C

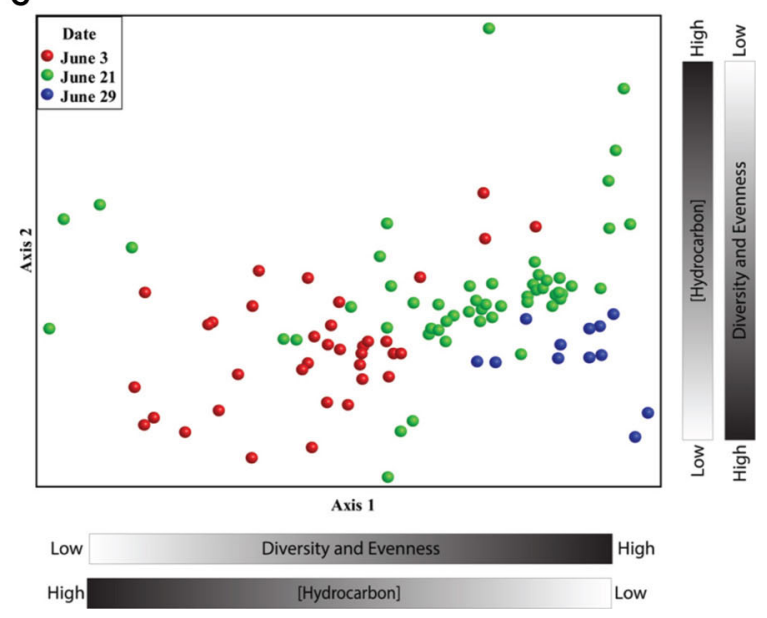

taxonomy. The ordination plot was rotated to maximize the degree of correlation with the time variable. A two dimensional solution was found and the final stress was 0.039. (C) Non-metric multidimensional scaling ordinations of sand samples based on the relative abundance pyrotag sequences assigned to family-level taxonomy. The ordination plot was rotated to maximize the degree of correlation with the time variable. A two dimensional solution was found and the final stress was 0.086 . we found that when the metatrascriptome data were compared to the SSU Greengenes database, $19.2 \%$ of sequences annotated at the genus level matched to Marinobacter.

Even though the samples were dominated by ribosomal genes, more than 100 million of the quality filtered reads were available for functional gene annotation. Nearly 17 million of these reads matched to the hydrocarbon gene database. A total of 3553 different matches to the hydrocarbon database were retrieved from the metatranscriptomics data with an average of 2357 reads mapping to each hit. Comparison of the unassembled data to the hydrocarbon gene database revealed that enzymes involved in degradation of a variety of hydrocarbons, including PAHs were expressed; including a variety of monoxygenases and dioxygenases, and those involved in converting PAHs to dihydrodiols 
(Supplemental Table S7). Genes involved in the pathway for gentisate and substituted gentisate degradation were also expressed. Gentisate is a central metabolite in the aerobic biodegradation of both simple and complex aromatic hydrocarbons.

Two of the metatranscriptomes were assembled (those from the June 3 and June 21 sampling dates) yielding approximately 350,000 and 150,000 contigs (>150 bp), respectively, (Supplemental Table S8) and the assemblies were also screened for hydrocarbon degradation genes. When the metatranscriptomes were searched for matches to reference genomes in the MG-RAST database, Marinobacter aquaeolei strain VT8 was the closest match (94\% average identity) (Figure 3). The most abundant xenobiotic degradation transcripts and overall functional transcripts matching to this strain were cyclohexanone monooxygenase, naphthyl-2-methylsuccinyl-CoA dehydrogenase, naphthyl-2-methylsuccinyl-CoA dehydrogenase, 3-hydroxyacyl-CoA dehydrogenase/ enoyl-CoA hydratase, and a succinate dehydrogenase complex (Table 1). Genes involved in motility were amongst the most abundant features of all contigs mapping to M. aquaeolei and included the CheA signal transduction histidine kinase involved in chemotaxis signaling and a flagellar hook-associated 2 domain-containing protein (Table 1).

Besides M. aquaeolei, xenobiotic degradation transcripts mapped to several other Proteobacteria isolates in the MG-RAST database. For example, transcripts matched to PAH (Figure 4), $n$-alkane (Supplementary Figure S4A), and toluene degradation

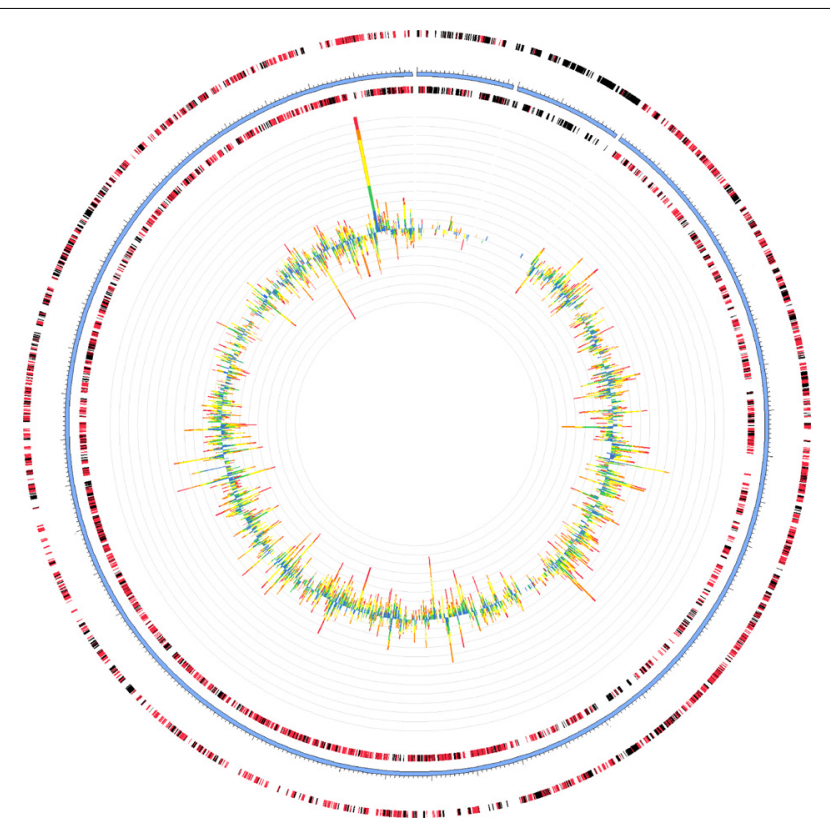

FIGURE 3 | Recruitment of June 3 metatranscriptome to Marinobacter aquaeolei strain VT8, the organism to which the largest number of contigs mapped for both metatranscriptomes. The genome is approximately $4.8 \mathrm{Mb}$ in size and the leading and lagging strands are represented by the outer most rings, separated by the blue ring, which indicates the position within the genome. Metatranscriptomic features are depicted as bar graphs inside the genome and their hit distribution is color-coded by e-value exponent as: blue, -3 to -5 ; green, -5 to -10 ; yellow, -10 to -20 ; orange, -20 to -30 ; red, less than -30 . Figure was generated using the MG-RAST recruitment plot tool. genes, matching to sequenced organisms in the Pseudomonadales, Burkholderiales, and Alteromonadales. Additionally, $\mathrm{PAH}$ (Figure 4), toluene, and benzoate pathways (Supplemental Figure S4B) mapped to members of the Rhodobacterales and toluene and benzoate metabolism transcripts mapped to Rhizobiales. It should be noted, that comparing metatranscriptomic data to KEGG pathways and organisms does not ascribe a complete pathway to a particular organism.

\section{ISOLATION OF OIL DEGRADING STRAINS FROM THE CONTAMINATED BEACH SAMPLES}

Enrichment with oil-contaminated samples from the sampling location resulted in isolation of 18 unique bacterial strains belonging almost entirely to the Gammaproteobacteria. 16S rRNA gene sequencing revealed that almost half of the isolates shared highest sequence homology to members of the Pseudomonadales, including Pseudomonas stutzeri, Pseudomonas pachastrellae, and Pseudomonas alcaligenes (Table 2). Three isolates belonging to the Marinobacter genus were retrieved from the more contaminated samples. Isolates having $>99 \%$ sequence homology to known Alcanivorax, Vibrio, Rheinheimera, and Bacillus sp. were also retrieved from these samples. Most of the isolates were halophilic, Gram-negative organisms, and showed the potential for degrading the MC252 oil.

Because of their high relative abundance in the 16S rRNA gene data in contaminated samples, two representative isolates, 33 (Marinobacter spp.) and 36 (Roseobacter spp.) were selected for their ability to grow using MC252 as the carbon source. Total hydrocarbons were extracted at selected time points and straight chain alkanes and PAHs (Figure 5) were depleted during the

Table 1 | Top xenobiotic and overall metatranscriptomic functions mapping to Marinobacter aquaeolei.

\begin{tabular}{|c|c|c|}
\hline \multirow[t]{2}{*}{ Function } & Relative & Relative \\
\hline & \multicolumn{2}{|c|}{ abundance June $3^{*}$ abundance June $21^{*}$} \\
\hline \multicolumn{3}{|l|}{ XENOBIOTIC } \\
\hline $\begin{array}{l}\text { Cyclohexanone } \\
\text { monooxygenase }\end{array}$ & 0.382 & 0.114 \\
\hline $\begin{array}{l}\text { Naphthyl-2-methylsuccinyl- } \\
\text { CoA } \\
\text { dehydrogenase }\end{array}$ & 0.318 & 0.795 \\
\hline Glutathione S-transferase & 0.255 & 0.000 \\
\hline $\begin{array}{l}\text { 3-hydroxyacyl-CoA } \\
\text { dehydrogenase / enoyl-CoA } \\
\text { hydratase }\end{array}$ & 0.191 & 0.568 \\
\hline Succinate dehydrogenase & 0.085 & 0.455 \\
\hline \multicolumn{3}{|l|}{ OVERALL } \\
\hline $\begin{array}{l}\text { CheA signal transduction } \\
\text { histidine kinase }\end{array}$ & 0.806 & 0.450 \\
\hline $\begin{array}{l}\text { Flagellar hook-associated } 2 \\
\text { domain-containing protein }\end{array}$ & 0.467 & 0.340 \\
\hline Elongation factor Tu & 0.042 & 1.023 \\
\hline Tetratricopeptide TPR_4 & 0.361 & 0.909 \\
\hline
\end{tabular}

${ }^{*}$ Relative abundances are percentages of total reads mapping to Marinobacter aquaelei. 


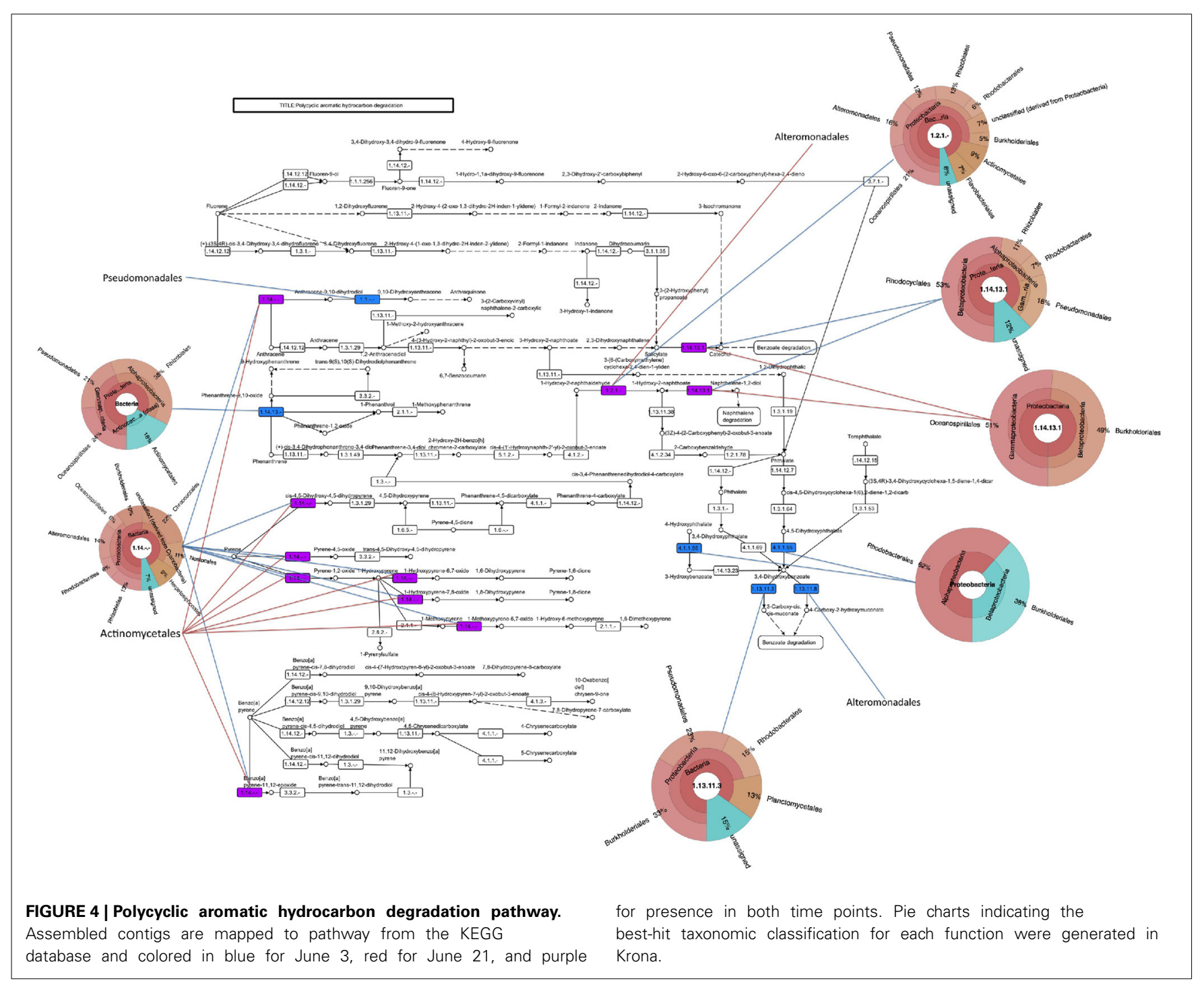

incubations for both cultures, although longer alkanes (C25 and longer) persisted after 15 and 20 days of incubation, respectively (Supplemental Figure S5). It should be noted that the MC252 source oil used in the incubations was already depleted in the lighter hydrocarbons at the start of the incubation (Supplemental Figure S6).

\section{DISCUSSION}

Macondo oil from the Deepwater Horizon oil spill that reached the shore of Elmer's Beach caused shifts in the indigenous microbial communities in the beach sand toward a hydrocarbon-degrading consortium. This observation is consistent with previous studies that have assessed the impact of oil spills on coastline microbial communities (Kasai et al., 2001; Maruyama et al., 2003; MedinaBellver et al., 2005; Alonso-Gutiérrez et al., 2009; Vila et al., 2010; Kostka et al., 2011). Kostka et al. (2011) also reported that highly contaminated samples exhibited higher bacterial cell densities than uncontaminated samples, and that there was a significant reduction in bacterial diversity associated with oil contamination. Here, we found that the contaminated samples collected from Elmer's Beach were generally dominated by Alpha- and Gammaproteobacteria (Figure 1) with up to $60 \%$ of the total microbial community being members of the Alphaproteobacteria. Other studies in the water column similarly reported a shortterm shift of microbial communities toward specific members of the Gammaproteobacteria as an immediate response to crude oil inputs, which were then succeeded within 1 month by members of the Alphaproteobacteria (Abed et al., 2002; Röling et al., 2002; Hernandez-Raquet et al., 2006; Hazen et al., 2010; Redmond and Valentine, 2011; Valentine et al., 2012; Dubinsky et al., 2013).

Microbial community analysis revealed increases in the abundance of the Rhodobacteraceae and Alteromonadaceae in both the beached surface oil and contaminated beach sand samples. Therefore the different contaminated samples collected from the beach shared a similar bacterial community composition at the family level and exhibited parallel temporal successional changes in bacterial community structures driven by hydrocarbon inputs. During the first two sampling points, members of the Alteromonadaceae, with high sequence identity to Marinobacter lutaoensis, were very abundant in samples with high 
Table 2 | Cultured Isolates retrieved from beached oil and contaminated beach sands.

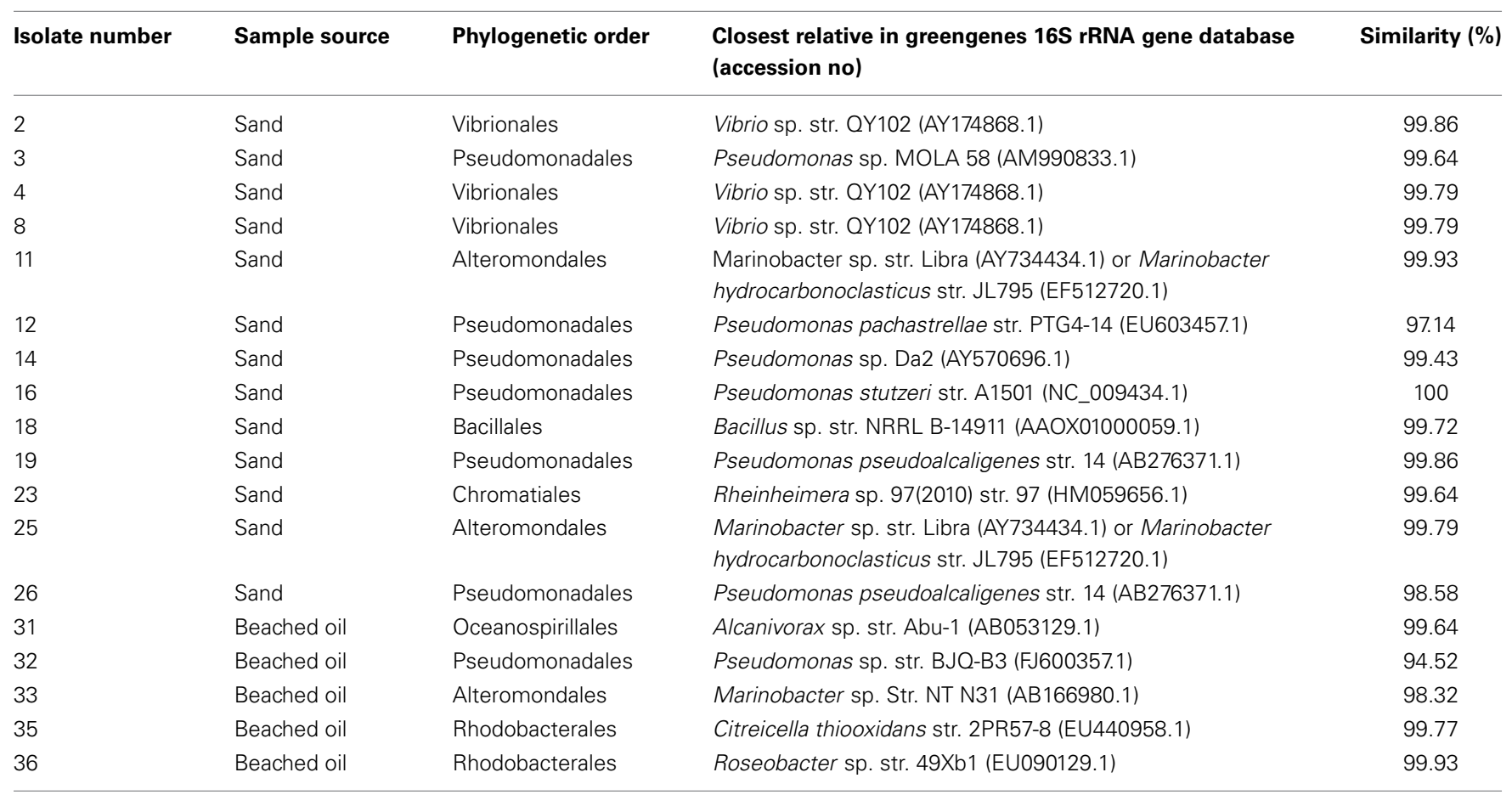

TPH concentrations. Members of the Marinobacter genus have previously been shown to be capable of degradation of both alkanes and $\mathrm{PAH}$ compounds with some isolates growing on single PAHs as their sole carbon source (Huu et al., 1999; Cohen, 2002; Shieh et al., 2003; Nicholson and Fathepure, 2004; Gerdes et al., 2005; Márquez and Ventosa, 2005; Brito et al., 2006; Gu et al., 2007; Cui et al., 2008; Rosano-Hernández and FernándezLinares, 2009; Vila et al., 2010; Wu et al., 2010; Dos Santos et al., 2011). Here we also successfully isolated Marinobacter strains from contaminated beach samples, which were capable of growth on MC252 oil as their sole carbon source. Several previous studies have reported the role of Marinobacter in degradation of oil (Gerdes et al., 2005; Vila et al., 2010; Kostka et al., 2011).The potential biodegradation of oil by these isolates at ambient temperature further supports their potential for natural biodegradation of oil in situ (Figure 5). However, it should be noted that further work is needed to determine the exact nature of the hydrocarbon transformations that occurred during the incubations and whether they were mineralized or transformed to other metabolites.

Several bacterial taxa within the Rhodobacteraceae were abundant in the highly contaminated samples. The Rhodobacteraceae are metabolically and ecologically diverse, comprised of photoheterotrophs that can grow, either, photoautotropically or chemotrophically, as well as chemoorganotrophs, fermenters, and methylotrophs. Several members of the Rhodobacteraceae have previously been identified in oil polluted soils and marine environments and in fact have been shown to dominate oil polluted environments of the North Sea (Brakstad and Lødeng, 2005) and Southeast Asia (Harwati et al., 2008, 2009a,b). A few studies have demonstrated that the addition of photosynthetic bacteria to oil-polluted wastewater and soil triggers an increase in the abundance of hydrocarbon-oxidizing bacteria and thus enhances the rate of oil degradation (Martínez-Alonso et al., 2004; Llirós et al., 2008). Additionally, our cultivation-based experiments revealed that one representative of the Rhodobacteraceae, Roseobacter isolate 36, was also able to grow on MC252 as its sole carbon source. Overall, our data suggested oil degradation on the surface of beach sand that is exposed to light may have been promoted naturally by increases in photosynthetic populations.

Additionally many Pseudomonas species, having highest sequence homology to $P$. pachastrellae, were abundant in our $16 \mathrm{~S}$ rRNA gene and cultivation experiments. Incidentally, similar pseudomonas strains were enriched from beach sands in the aftermath of both the Prestige oil spill in Northwestern Spain (Mulet et al., 2011) and other contaminated coastal sites during the Deepwater Horizon spill (Kostka et al., 2011) and these strains were shown to be central to the biodegradation of both aliphatic and aromatic hydrocarbons. Additionally, members of the Alcanivorax were abundant in the oil contaminated samples, corroborating previous $16 \mathrm{~S}$ rRNA-based studies (Kasai et al., 2002; Kostka et al., 2011; Chakraborty et al., 2012).

Metatranscriptome analyses revealed that members of the Alpha- and Gammaproteobacteria were active in hydrocarbon degradation. This is the first study to determine functional genes involved in hydrocarbon degradation that were expressed in beach samples during the Deepwater Horizon spill. This study highlighted that metatranscriptomic data mapped to hydrocarbon degrading genes, including those involved in PAH, benzoate, and $n$-alkane degradation from Alteromonadales, Pseudomonales, and Rhodobacterales genomes. Data also mapped to other hydrocarbon degradation genes, including monooxygenases, 

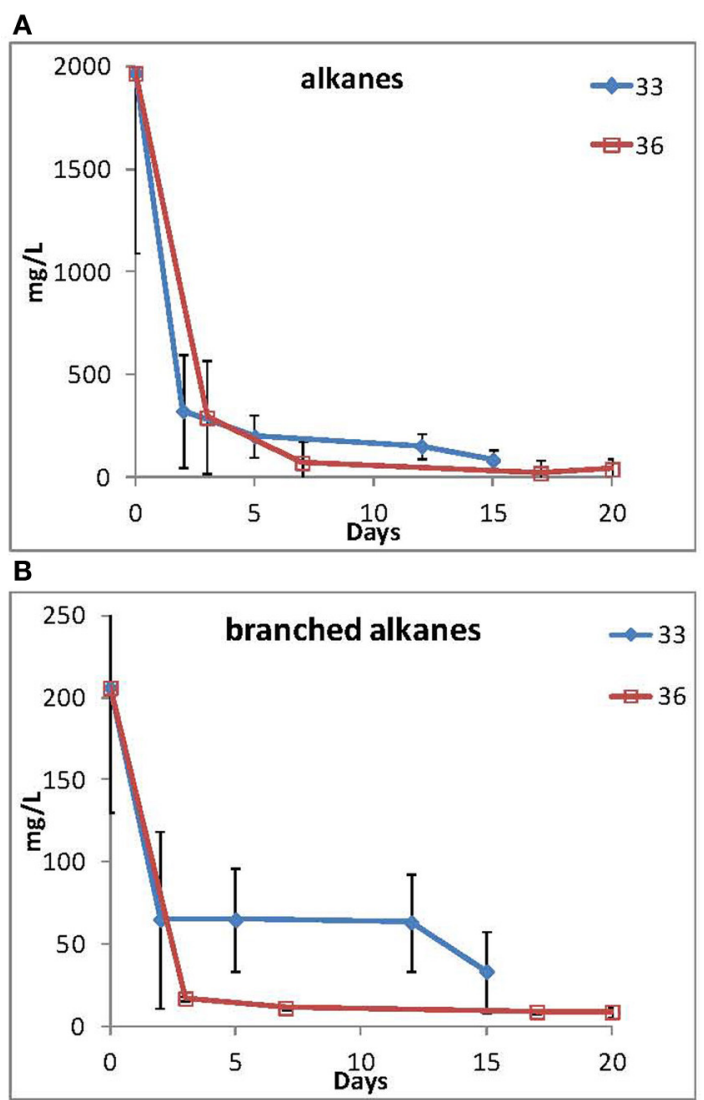
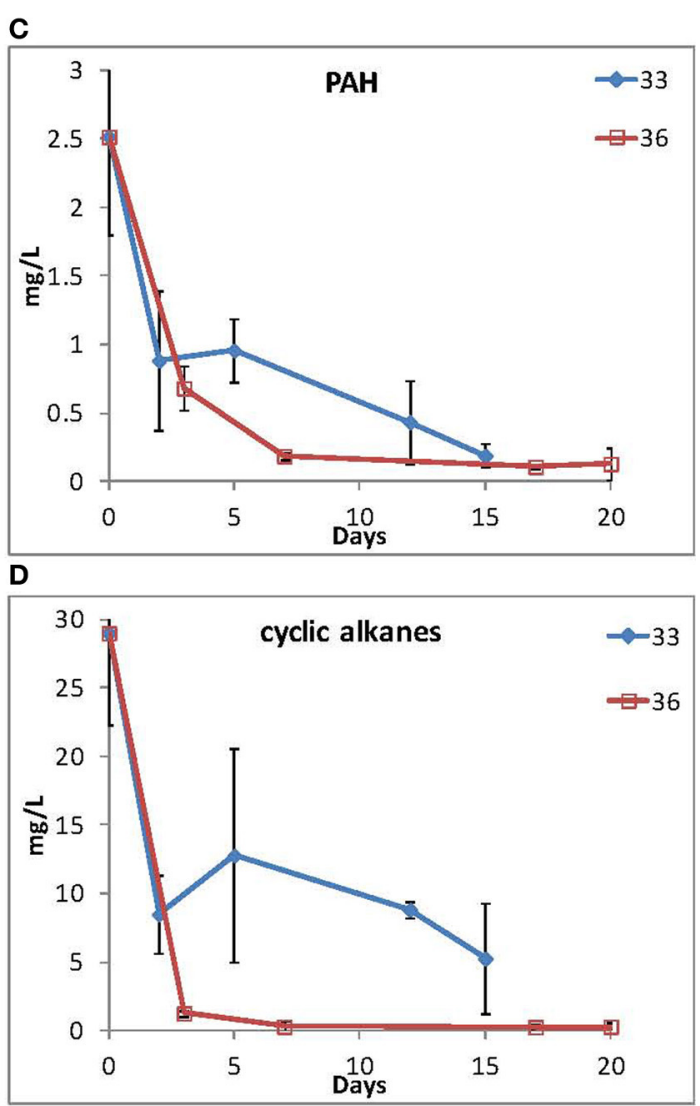

FIGURE 5 | Loss of (A) straight alkanes, (B) branched alkanes, (C) PAHs, and (D) cyclic alkanes during incubation by isolate 33 (Marinobacter spp.) and isolate 36 (Roseobacter spp.).

dioxygenases, dehydrogenases, and hydratases, from members of these microbial classes. While this analysis doesn't necessarily ascribe a complete pathway to a particular organism, these results suggest that not only are these microorganisms abundant in the beach microbial community as suggested by the 16S rRNA gene data, but they may also play an active role in hydrocarbon degradation.

Marinobacter aquaeolei strain VT8 was the bacterium in the reference genome database that had the highest abundance of expressed genes in the oil contaminated samples, including those for cyclohexanone monooxygenase and naphthyl-2methylsuccinyl-CoA dehydrogenase. In addition, transcripts for genes involved in chemotaxis and cellular motility mapped to Marinobacter suggesting that there was an active response to the hydrocarbon contamination in the beach communities, similar to the response observed for Oceanospirillales that were detected in the deep-sea plume (Mason et al., 2012). The high levels of gene expression observed for Marinobacter in the beach metatranscriptome data was supported by the finding that members of this genus were also enriched in the $16 \mathrm{~S}$ rRNA data. In addition, we successfully isolated a representative of Marinobacter from the contaminated beach samples and demonstrated the ability of the isolate to degrade MC252 oil. These data suggest that Marinobacter may have played a key role in degradation of the oil that reached the coast during the Deepwater Horizon oil spill.

\section{CONCLUSIONS}

During the Deepwater Horizon oil spill, MC252 oil originating from the Macondo well reached the coastline and Elmer's Beach was heavily impacted by the oil in June 2010, during which time we collected samples. Oil deposited on the shore appeared to cause a shift in the community structure toward a hydrocarbonoclastic consortia, as 16S rRNA gene sequencing demonstrated a diverse array of known petroleum hydrocarbon degrading microorganisms in these samples. Interestingly, several OTUs representative of previously described oil-degrading phototrophs were abundant in the heavily oiled samples from the first two sampling periods and these were succeeded by a diverse array of other potential oil-degrading bacteria. Metatranscriptome profiling revealed that members of the Alpha- and Gammaproteobacteria expressed genes for hydrocarbon degradation in the contaminated samples, suggesting that they played a key role in potential degradation processes. Of note, Marinobacter were abundant members of the community in the oil-contaminated samples and expressed genes for degradation of hydrocarbons. Compared to other oil spills that have impacted shorelines, such as the Prestige oil spill that occurred in 
a cold pristine habitat, the disappearance of MC252 oil seemed more rapid. This difference in microbial response could be due to differences in temperatures between the two sites as well as differences in other environmental variables, including previous exposure to oil spills. Overall, this study of the microbial community response on the Gulf shoreline may assist in the understanding of microbial proxies for oil contamination in similar coastal ecosystems.

\section{AUTHOR CONTRIBUTIONS}

Regina Lamendella, Janet K. Jansson, and Terry C. Hazen were responsible for study conception and design. Regina Lamendella, Steven Strutt, and Janet K. Jansson were responsible for manuscript preparation. Sharon Borglin was responsible for chemical analyses. Romy Chakraborty was responsible for cultivation experiments. Regina Lamendella and Jenni Hultman were responsible for $16 \mathrm{~S}$ RNA gene and metatranscriptomics experiments. Regina Lamendella, Steven Strutt, Olivia U. Mason, Emmanuel Prestat, and Neslihan Tas were responsible for bioinformatics and biostatistical analyses.

\section{ACKNOWLEDGMENTS}

This work was supported by a subcontract from the University of California at Berkeley, Energy Biosciences Institute to Lawrence Berkeley National Laboratory under its U.S. Department of Energy contract DE-AC02-05CH11231. The Energy Biosciences Institute to UC Berkeley is supported by a grant from British Petroleum. We acknowledge support from Theresa Pollard, Yvette Piceno and Dominique Joyner with ordering, and transportation of supplies and samples to and from the field.

\section{SUPPLEMENTARY MATERIAL}

The Supplementary Material for this article can be found online at: http://www.frontiersin.org/journal/10.3389/fmicb. 2014.00130/abstract

\section{REFERENCES}

Abed, R. M. M., Safi, N. M. D., Köster, J., Beer, D. de, El-Nahhal, Y., Rullkötter, J. et al. (2002). Microbial diversity of a Heavily polluted microbial mat and its community changes following degradation of petroleum compounds. Appl. Environ. Microbiol. 68, 1674-1683. doi: 10.1128/AEM.68.4.16741683.2002

Allgaier, M., Reddy, A., Park, J. I., Ivanova, N., D’haeseleer, P., Lowry, S. et al. (2010). Targeted discovery of glycoside hydrolases from a switchgrass-adapted compost community. PLoS ONE 5:e8812. doi: 10.1371/journal.pone.0008812

Alonso-Gutiérrez, J., Figueras, A., Albaigés, J., Jiménez, N., Viñas, M., Solanas, A. M., et al. (2009). Bacterial communities from shoreline environments (Costa da Morte, Northwestern Spain) affected by the prestige oil spill. Appl. Environ. Microbiol. 75, 3407-3418. doi: 10.1128/AEM.01776-08

Baelum, J., Borglin, S., Chakraborty, R., Fortney, J. L., Lamendella, R., Mason, O. U., et al. (2012). Deep-sea bacteria enriched by oil and dispersant from the Deepwater Horizon spill. Environ. Microbiol. 14, 2405-2416. doi: 10.1111/j.1462-2920.2012.02780.x

Brakstad, O. G., and Lødeng, A. G. G. (2005). Microbial diversity during biodegradation of crude oil in seawater from the North Sea. Microb. Ecol. 49, 94-103. doi: 10.1007/s00248-003-0225-6

Brito, E. M. S., Guyoneaud, R., Goñi-Urriza, M., Ranchou-Peyruse, A., Verbaere, A., Crapez, M. A. C., et al. (2006). Characterization of hydrocarbonoclastic bacterial communities from mangrove sediments in Guanabara Bay, Brazil. Res. Microbiol. 157, 752-762. doi: 10.1016/j.resmic.2006.03.005
Camilli, R., Reddy, C. M., Yoerger, D. R., Van Mooy, B. A. S., Jakuba, M. V., Kinsey, J. C., et al. (2010). Tracking hydrocarbon plume transport and biodegradation at deepwater horizon. Science 330, 201-204. doi: 10.1126/science.1195223

Caporaso, J. G., Kuczynski, J., Stombaugh, J., Bittinger, K., Bushman, F. D., Costello, E. K., et al. (2010). QIIME allows analysis of high-throughput community sequencing data. Nat. Methods 7, 335-336. doi: 10.1038/nmeth.f.303

Chakraborty, R., Borglin, S. E., Dubinsky, E. A., Andersen, G. L., and Hazen, T. C. (2012). Microbial Response to the MC-252 Oil and Corexit 9500 in the Gulf of Mexico. Front. Microbiol. 3:357. doi: 10.3389/fmicb.2012.00357

Coates, J. D., Lonergan, D. J., Philips, E. J. P., Jenter, H., and Lovley, D. R. (1995). Desulfuromonas palmitatis sp. nov., a marine dissimilatory $\mathrm{Fe}(\mathrm{III})$ reducer that can oxidize long-chain fatty acids. Arch. Microbiol. 164, 406-413. doi: 10.1007/BF02529738

Cohen, Y. (2002). Bioremediation of oil by marine microbial mats. Int. Microbiol. Off. J. Span. Soc. Microbiol. 5, 189-193. doi: 10.1007/s10123-002-0089-5

Cui, Z., Lai, Q., Dong, C., and Shao, Z. (2008). Biodiversity of polycyclic aromatic hydrocarbon-degrading bacteria from deep sea sediments of the Middle Atlantic Ridge. Environ. Microbiol. 10, 2138-2149. doi: 10.1111/j.14622920.2008.01637.x

DeSantis, T. Z., Hugenholtz, P., Larsen, N., Rojas, M., Brodie, E. L., Keller, K., et al. (2006). Greengenes, a Chimera-Checked 16S rRNA gene database and workbench compatible with ARB. Appl. Environ. Microbiol. 72, 5069-5072. doi: 10.1128/AEM.03006-05

Dos Santos, H. F., Cury, J. C., do Carmo, F. L., dos Santos, A. L., Tiedje, J., van Elsas, J. D., et al. (2011). Mangrove bacterial diversity and the impact of oil contamination revealed by pyrosequencing: bacterial proxies for oil pollution. PLoS ONE 6:e16943. doi: 10.1371/journal.pone.0016943

Dubinsky, E. A., Conrad, M. E., Chakraborty, R., Bill, M., Borglin, S. E., Hollibaugh, J. T., et al. (2013). Succession of hydrocarbon-degrading bacteria in the aftermath of the deepwater horizon oil spill in the Gulf of Mexico. Environ. Sci. Technol. 47, 10860-10867. doi: 10.1021/es401676y

Gerdes, B., Brinkmeyer, R., Dieckmann, G., and Helmke, E. (2005). Influence of crude oil on changes of bacterial communities in Arctic sea-ice. FEMS Microbiol. Ecol. 53, 129-139. doi: 10.1016/j.femsec.2004.11.010

Greenwood, P. F., and Georges, S. C. (1999). Mass spectral characteristics of C19 and C20 tricyclic terpanes detected in Latrobe tasmanite oil shale. Eur. Mass Spectrom. 5, 221-230. doi: 10.1255/ejms.278

Gu, J., Cai, H., Yu, S.-L., Qu, R., Yin, B., Guo, Y.-F., et al. (2007). Marinobacter gudaonensis sp. nov., isolated from an oil-polluted saline soil in a Chinese oilfield. Int. J. Syst. Evol. Microbiol. 57, 250-254. doi: 10.1099/ijs.0.64522-0

Harwati, T. U., Kasai, Y., Kodama, Y., Susilaningsih, D., and Watanabe, K. (2008). Tranquillimonas alkanivorans gen. nov., sp. nov., an alkane-degrading bacterium isolated from Semarang Port in Indonesia. Int. J. Syst. Evol. Microbiol. 58, 2118-2121. doi: 10.1099/ijs.0.65817-0

Harwati, T. U., Kasai, Y., Kodama, Y., Susilaningsih, D., and Watanabe, K. (2009a). Tropicibacter naphthalenivorans gen. nov., sp. nov., a polycyclic aromatic hydrocarbon-degrading bacterium isolated from Semarang Port in Indonesia. Int. J. Syst. Evol. Microbiol. 59, 392-396. doi: 10.1099/ijs.0.65821-0

Harwati, T. U., Kasai, Y., Kodama, Y., Susilaningsih, D., and Watanabe, K. (2009b). Tropicimonas isoalkanivorans gen. nov., sp. nov., a branched-alkane-degrading bacterium isolated from Semarang Port in Indonesia. Int. J. Syst. Evol. Microbiol. 59, 388-391. doi: 10.1099/ijs.0.65822-0

Hauser, A., Dashti, H., and Khan, Z. H. (1999). Identification of biomarker compounds in selected Kuwait crude oils. Fuel 78, 1483-1488. doi: 10.1016/S00162361(99)00075-7

Hazen, T. C., Dubinsky, E. A., DeSantis, T. Z., Andersen, G. L., Piceno, Y. M., Singh, N., et al. (2010). Deep-sea oil plume enriches indigenous oil-degrading bacteria. Science 330, 204-208. doi: 10.1126/science.1195979

Hernandez-Raquet, G., Budzinski, H., Caumette, P., Dabert, P., Le Ménach, K., Muyzer, G., et al. (2006). Molecular diversity studies of bacterial communities of oil polluted microbial mats from the Etang de Berre (France). FEMS Microbiol. Ecol. 58, 550-562. doi: 10.1111/j.1574-6941.2006.00187.x

Huu, N. B., Denner, E. B., Ha, D. T., Wanner, G., and Stan-Lotter, H. (1999). Marinobacter aquaeolei sp. nov., a halophilic bacterium isolated from a Vietnamese oil-producing well. Int. J. Syst. Bacteriol. 49(Pt 2), 367-375.

Hyatt, D., Chen, G.-L., LoCascio, P. F., Land, M. L., Larimer, F. W., and Hauser, L. J. (2010). Prodigal: prokaryotic gene recognition and translation initiation site identification. BMC Bioinformatics 11:119. doi: 10.1186/1471-210511-119 
Kanehisa, M., and Goto, S. (2000). KEGG: kyoto encyclopedia of genes and genomes. Nucleic Acids Res. 28, 27-30. doi: 10.1093/nar/28.1.27

Kasai, Y., Kishira, H., Sasaki, T., Syutsubo, K., Watanabe, K., and Harayama, S. (2002). Predominant growth of Alcanivorax strains in oil-contaminated and nutrient-supplemented sea water. Environ. Microbiol. 4, 141-147. doi: 10.1046/j.1462-2920.2002.00275.x

Kasai, Y., Kishira, H., Syutsubo, K., and Harayama, S. (2001). Molecular detection of marine bacterial populations on beaches contaminated by the Nakhodka tanker oil-spill accident. Environ. Microbiol. 3, 246-255. doi: 10.1046/j.14622920.2001.00185.x

Kimes, N. E., Callaghan, A. V., Aktas, D. F., Smith, W. L., Sunner, J., Golding, B., et al. (2013). Metagenomic analysis and metabolite profiling of deep-sea sediments from the Gulf of Mexico following the Deepwater Horizon oil spill. Front. Microbiol. 4:50. doi: 10.3389/fmicb.2013.00050

Klukas, C., and Schreiber, F. (2007). Dynamic exploration and editing of KEGG pathway diagrams. Bioinformatics 23, 344-350. doi: 10.1093/bioinformatics/btl611

Kostka, J. E., Prakash, O., Overholt, W. A., Green, S. J., Freyer, G., Canion, A., et al. (2011). Hydrocarbon-degrading bacteria and the bacterial community response in Gulf of Mexico beach sands impacted by the deepwater horizon oil spill. Appl. Environ. Microbiol. 77, 7962-7974. doi: 10.1128/AEM.05402-11

Kunin, V., and Hugenholtz, P. (2010). PyroTagger: a fast, accurate pipeline for analysis of rRNA amplicon pyrosequence data. Open J. 1, 1-8. Available online at: http://www.theopenjournal.org/toj_articles/1

Kunin, V., Engelbrektson, A., Ochman, H., and Hugenholtz, P. (2010). Wrinkles in the rare biosphere: pyrosequencing errors can lead to artificial inflation of diversity estimates. Environ. Microbiol. 12, 118-123. doi: 10.1111/j.14622920.2009.02051.x

Llirós, M., Gaju, N., de Oteyza, T. G., Grimalt, J. O., Esteve, I., and MartínezAlonso, M. (2008). Microcosm experiments of oil degradation by microbial mats. II. The changes in microbial species. Sci. Total Environ. 393, 39-49. doi: 10.1016/j.scitotenv.2007.11.034

Lubchenco, J., McNutt, M., Lehr, B., Sogge, M., Miller, M., Hammond, S., et al. (2010). Deepwater Horizon/BP Oil Budget: What Happened to the Oil? Available online at: http://www.noaanews.noaa.gov/stories2010/PDFs/ OilBudget_description_\%2083final.pdf

Márquez, M. C., and Ventosa, A. (2005). Marinobacter hydrocarbonoclasticus Gauthier et al. 1992 and Marinobacter aquaeolei Nguyen et al. 1999 are heterotypic synonyms. Int. J. Syst. Evol. Microbiol. 55, 1349-1351. doi: 10.1099/ijs.0.63591-0

Martínez-Alonso, M., de Oteyza, T. G., Llirós, M., Munill, X., Muyzer, G., Esteve, I., et al. (2004). Diversity shifts and crude oil transformation in polluted microbial mat microcosms. Ophelia 58, 205-216. doi: 10.1080/00785236.2004.10410228

Maruyama, A., Ishiwata, H., Kitamura, K., Sunamura, M., Fujita, T., Matsuo, M., et al. (2003). Dynamics of microbial populations and strong selection for Cycloclasticus pugetii following the Nakhodka oil spill. Microb. Ecol. 46, 442-453. doi: 10.1007/s00248-002-3010-z

Mason, O. U., Hazen, T. C., Borglin, S., Chain, P. S. G., Dubinsky, E. A., Fortney, J. L., et al. (2012). Metagenome, metatranscriptome and single-cell sequencing reveal microbial response to Deepwater Horizon oil spill. ISME J. 6, 1715-1727. doi: 10.1038/ismej.2012.59

Mason, O. U., Scott, N. M., Gonzalez, A., Robbins-Pianka, A., Bælum, J., Kimbrel, J., et al. (2014). Metagenomics reveals sediment microbial community response to Deepwater Horizon oil spill. ISME J. doi: 10.1038/ismej.2013.254. [Epub ahead of print].

McCrea-Strub, A., Kleisner, K., Sumaila, U. R., Swartz, W., Watson, R., Zeller, D., et al. (2011). Potential impact of the Deepwater Horizon oil spill on commercial fisheries in the Gulf of Mexico. Fisheries 36, 332-336. doi: $10.1080 / 03632415.2011 .589334$

McCune, B., Grace, J. B., and Urban, D. L. (2002). Analysis of Ecological Communities. Corvallis, OR: MjM Software Design.

Medina-Bellver, J. I., Marín, P., Delgado, A., Rodríguez-Sánchez, A., Reyes, E., Ramos, J. L., et al. (2005). Evidence for in situ crude oil biodegradation after the prestige oil spill. Environ. Microbiol. 7, 773-779. doi: 10.1111/j.14622920.2005.00742.x

Meyer, F., Paarmann, D., D’Souza, M., Olson, R., Glass, E. M., Kubal, M., et al. (2008). The metagenomics RAST server - a public resource for the automatic phylogenetic and functional analysis of metagenomes. BMC Bioinformatics 9:386. doi: 10.1186/1471-2105-9-386
Miller, D. N., Bryant, J. E., Madsen, E. L., and Ghiorse, W. C. (1999). Evaluation and optimization of DNA Extraction and purification procedures for soil and sediment samples. Appl. Environ. Microbiol. 65, 4715-4724.

Mulet, M., David, Z., Nogales, B., Bosch, R., Lalucat, J., and García-Valdés, E. (2011). Pseudomonas diversity in crude-oil-contaminated intertidal sand samples obtained after the prestige oil spill. Appl. Environ. Microbiol. 77, 1076-1085. doi: 10.1128/AEM.01741-10

Nicholson, C. A., and Fathepure, B. Z. (2004). Biodegradation of benzene by halophilic and halotolerant bacteria under aerobic conditions. Appl. Environ. Microbiol. 70, 1222-1225. doi: 10.1128/AEM.70.2.1222-1225.2004

Ondov, B. D., Bergman, N. H., and Phillippy, A. M. (2011). Interactive metagenomic visualization in a Web browser. BMC Bioinformatics 12:385. doi: 10.1186/1471-2105-12-385

OSAT-2. (2011). Summary Report for Fate and Effects of Remnant Oil in the Beach Environment. Operational Science Advisory Team, Deepwater Horizon MC252. Prepared for Federal On-Scene Coordinator. Available online at: http://www.dep.state.fl.us/deepwaterhorizon/files2/osat_2_report_10feb.pdf

Parks, D. H., and Beiko, R. G. (2010). Identifying biologically relevant differences between metagenomic communities. Bioinforma. Oxf. Engl. 26, 715-721. doi: 10.1093/bioinformatics/btq041.

Redmond, M. C., and Valentine, D. L. (2011). Natural gas and temperature structured a microbial community response to the Deepwater Horizon oil spill. Proc. Natl. Acad. Sci. U.S.A. doi: 10.1073/pnas.110875610

Röling, W. F. M., Milner, M. G., Jones, D. M., Lee, K., Daniel, F., Swannell, R. J. P., et al. (2002). Robust hydrocarbon degradation and dynamics of bacterial communities during nutrient-enhanced oil spill bioremediation. Appl. Environ. Microbiol. 68, 5537-5548. doi: 10.1128/AEM.68.11.55375548.2002

Rosano-Hernández, M. C., and Fernández-Linares, L. C. (2009). Bacterial diversity of marine seeps in the southeastern Gulf of Mexico. Pak. J. Biol. Sci. 12, 683-689. doi: 10.3923/pjbs.2009.683.689

Rosenbauer, R. J., Campbell, P. L., Lam, A., Lorenson, T. D., Hostettler, F. D., Thomas, B., et al. (2010). Reconnaissance of Macondo-1 Well Oil in Sediment and Tarballs from the Northern Gulf of Mexico shoreline, Texas to Florida. United States Geological Survey. Available online at: http://pubs.usgs.gov/of/2010/1290/

Shieh, W. Y., Jean, W. D., Lin, Y.-T., and Tseng, M. (2003). Marinobacter lutaoensis sp. nov., a thermotolerant marine bacterium isolated from a coastal hot spring in Lutao, Taiwan. Can. J. Microbiol. 49, 244-252. doi: 10.1139/w03-032.

Sistrom, W. R. (1962). The Kinetics of the Synthesis of Photopigments in Rhodopseudomonas spheroides. J. Gen. Microbiol. 28, 607-616. doi: 10.1099/00221287-28-4-607

Sumaila, U. R., Cisneros-Montemayor, A. M., Dyck, A., Huang, L., Cheung, W., Jacquet, J., et al. (2012). Impact of the Deepwater Horizon well blowout on the economics of US Gulf fisheries. Can. J. Fish. Aquat. Sci. 69, 499-510. doi: 10.1139/f2011-171.

The Federal Intragency Solutions Group: Oil Budget Calculator Science and Engineering Team (2010). Oil Budget Calculator Deepwater Horizon.

US Coast Guard, USGS, and NOAA. (2010). Deepwater Horizon MC252 Gulf Incident Oil Budget. Available online at: http://www.usgs.gov/foia/budget/ 08-02-2010.Deepwater\%20Horizon\%20Oil\%20Budget.pdf

Valentine, D. L., Kessler, J. D., Redmond, M. C., Mendes, S. D., Heintz, M. B., Farwell, C., et al. (2010). Propane respiration jump-starts microbial response to a deep oil spill. Science 330, 208-211. doi: 10.1126/science.1196830

Valentine, D. L., Mezic, I., Macesic, S., Crnjaric-Zic, N., Ivic, S., Hogan, P. J., et al. (2012). Dynamic autoinoculation and the microbial ecology of a deep water hydrocarbon irruption. Proc. Natl. Acad. Sci. U.S.A. 109, 20286-20291. doi: 10.1073/pnas.1108820109

Venosa, A. D., Suidan, M. T., King, D., and Wrenn, B. A. (1997). Use of hopane as a conservative biomarker for monitoring the bioremediation effectiveness of crude oil contaminating a sandy beach. J. Ind. Microbiol. Biotechnol. 18, 131-139. doi: 10.1038/sj.jim.2900304

Vila, J., María Nieto, J., Mertens, J., Springael, D., and Grifoll, M. (2010). Microbial community structure of a heavy fuel oil-degrading marine consortium: linking microbial dynamics with polycyclic aromatic hydrocarbon utilization. FEMS Microbiol. Ecol. 73, 349-362. doi: 10.1111/j.1574-6941.2010.00 902.x

Volkman, J. K., Alexander, R., Kagi, R. I., and Rullkötter, J. (1983). GC-MS characterisation of $\mathrm{C} 27$ and C28 triterpanes in sediments and petroleum. Geochim. Cosmochim. Acta 47, 1033-1040. doi: 10.1016/0016-7037(83)90233-8 
Wu, C., Wang, X., and Shao, Z. (2010). Diversity of oil-degrading bacteria isolated form the Indian Ocean sea surface. Wei Sheng Wu Xue Bao 50, 1218-1225.

Yakimov, M. M., Golyshin, P. N., Lang, S., Moore, E. R., Abraham, W. R., Lünsdorf, H., et al. (1998). Alcanivorax borkumensis gen. nov., sp. nov., a new, hydrocarbon-degrading and surfactant-producing marine bacterium. Int. J. Syst. Bacteriol. 48(Pt 2), 339-348. doi: 10.1099/0020771348-2-339

Zukunft, P. (2010). Summary Report for Sub-Sea and Sub-Surface Oil and Disperion Detection: Sampling and Monitoring. Available online at: http://www.restorethegulf.gov/sites/default/files/documents/pdf/OSAT_Report_ FINAL_17DEC.pdf

Conflict of Interest Statement: The authors declare that the research was conducted in the absence of any commercial or financial relationships that could be construed as a potential conflict of interest.
Received: 20 November 2013; accepted: 13 March 2014; published online: 03 April 2014.

Citation: Lamendella R, Strutt S, Borglin S, Chakraborty R, Tas N, Mason OU, Hultman J, Prestat E, Hazen TC and Jansson JK (2014) Assessment of the Deepwater Horizon oil spill impact on Gulf coast microbial communities. Front. Microbiol. 5:130. doi: 10.3389/fmicb.2014.00130

This article was submitted to Virology, a section of the journal Frontiers in Microbiology.

Copyright (c) 2014 Lamendella, Strutt, Borglin, Chakraborty, Tas, Mason, Hultman, Prestat, Hazen and Jansson. This is an open-access article distributed under the terms of the Creative Commons Attribution License (CC BY). The use, distribution or reproduction in other forums is permitted, provided the original author(s) or licensor are credited and that the original publication in this journal is cited, in accordance with accepted academic practice. No use, distribution or reproduction is permitted which does not comply with these terms. 